\title{
Measuring (and Increasing) the Value of Academic Libraries"
}

\author{
Carol Tenopir** \\ Donald W. King***

\begin{tabular}{|l|l|}
\cline { 2 - 2 } & \multicolumn{1}{|c|}{ Contents } \\
1. Introduction & 4. Return on Investment \\
2. Methods & 5. Administrators' Priorities \\
3. Critical Incident of Last Article & 6. Lib-Value \\
Reading & 7. Conclusion \\
\hline
\end{tabular}

\section{ABSTRACT}

The value of the university library to faculty, students, and administrators has long been assumed. In an era of decreasing resources and increasing choices, academic librarians must now find the best ways to measure and demonstrate the value of the library to all of their stakeholders, including faculty members, graduate students, undergraduate students, administrators, and funders. Techniques to assess and measure value can also help library decision makers select the products and services that provide the highest return on investment (ROI) to the university community. It is important to measure and convey the value of the academic library; it is also possible to increase the value of the library to the university by carefully refocusing the academic library's products and services.

In this presentation I will discuss methods and results from a recently completed study in eight countries that measured the value and ROI of e-journals to the grants process. The Return on Investment (ROI) of the e-journals collection to grant funding ranged from over 15:1 to just under 1:1 in 9 institutions. In addition, many other qualitative and quantitative measures of value are as important as derived measures like ROI. Building on that research study, I am now leading a team that includes the Association of Research Libraries (ARL) and several university libraries in a project funded by the U.S. Institute of Museum and Library Services. We are collecting data using on the value of a wide range of library services using several methods for measuring the value of what the university library contributes to the institution and its stakeholders.

Keywords: University Library, USA, Value, Reading, Critical Incident Technique, Return On Investment(ROI)

* The paper was originally presented at the International Conference commemorating the 40th Anniversary of the Korean Society for Library and Information Science held in Seoul, Korea on October 8, 2010.

** Chancellor's Professor, School of Information Sciences and Director of Research, College of Communication and Information University of Tennessee, USA(ctenopir@utk.edu)

*** University of Tennessee and Bryant University, Smithfield, RI, USA 논문접수일자: 2010년 8월 29일 최초심사일자: 2010년 9월 16일 게재확정일자: 2010년 10월 6일 한국문헌정보학회지, 44(4): 19-31, 2010. [DOI:10.4275/KSLIS.2010.44.4.019] 


\section{Introduction}

The value of the university library to faculty, students, and administrators has long been assumed. In an era of decreasing resources and increasing choices, academic librarians must now find the best ways to measure and demonstrate the value of the library to all of their stakeholders, including faculty members, graduate students, undergraduate students, administrators, and funders. Techniques to assess and measure value can also help library decision makers select the products and services that provide the highest return on investment to the university community. It is important to measure and convey the value of the academic library; it is also possible to increase the value of the library to the university by carefully refocusing the academic library's products and services. Input measures, such as volumes held, are no longer sufficient indicators of value; libraries today must provide a variety of measures of outcomes, impact, and value (Matthews, 2007).

\section{Methods}

Many methods can be used to measure the current value of library products and services. Library assessment plans should include a mix of methods employed on a schedule over time. Some of these major methods include:

- Measuring amount of use of e-collections through usage logs or vendor usage reports,

- Measuring perceived value or ways to increase value in the future through surveys or focus groups,

- Measuring tradeoffs of what services are the most valuable through techniques such as conjoint measurement,

- Calculating contingent valuation (demonstrating the cost of not having the library) through interviews and data collection, and

- Calculating the contribution of library collections and services through Return on Investment (ROI).

Measuring usage through downloads or usage logs provide an implicit measure of value. It is assumed that because libraries are used, they are of value to the users. With electronic collections, there are several ways to collect data about use, including usage logs, vendor reports 
(specifically COUNTER-compliant reports), and surveys of use (Nicholas et al, 2006; Tenopir et al, 2007). Usage of e-resources is relatively easy to measure on an ongoing basis and is especially useful in collection development decisions and comparison of specific journal titles or use across subject disciplines.

Neither logs nor vendor reports show purpose, satisfaction, or outcomes of use, however. Nor do they show any use of resources in the library's print collection or use of resources beyond the library's e-collections. Because of this, usage logs and reports do not allow relative comparison of the value of the library with alternative sources. To measure value beyond just usage, other methods must be employed. Explicit methods of measuring value include qualitative interview techniques that ask faculty members, students, or others specifically about the value or outcomes attributed to their use of the library collections or services and surveys or interviews that focus on a specific (critical) incident of use (Tenopir \& King, 2007). Derived values, such as ROI, provide an increased depth of analysis using multiple types of data.

This paper focuses on two main methods for demonstrating explicit or derived measures of value, purpose, and outcomes from library journal collections: surveys using critical incident technique and calculating Return on Investment. For further information and more in-depth discussions of methods, see Tenopir et al, 2009a; Tenopir \& King, 2007; Tenopir \& King, 2000; Tenopir et al, 2010; Luther, 2008; Tenopir, 2009a.

Links to many previous studies that measure value, outcome, or ROI in libraries are available at the IMLS "Lib-Value" project website at the University of Tennessee (libvalue.cci.utk.edu). Studies described in the project's bibliographic database include multiple methods for academic, special, and public library value studies.

\section{Critical Incident of Last Article Reading}

Surveys by Tenopir \& King from 1977 to the present measure purpose, outcomes, and value of article readings. These studies allow comparison of the relative value of the library, by including readings from print and electronic library collections, personal subscriptions, the open web, and other alternative sources of articles. These surveys use a variation of the critical incident technique and:

- Have respondents focus on a specific reading (last incident of reading). This increases the likelihood that their memory will be better and provides a second-stage random sample 
of readings in addition to the first stage sample of readers.

- Include all reading--electronic and print, library collections and personal subscriptions and from the web-to allow comparison of the value of the library collections with other sources of information.

- Ask questions about the purpose, motivation, and outcomes from this reading to allow a more detailed examination of value (Tenopir \& King, 2007).

Critical incident can be used to show value of use, as well as just frequency of use. It can be used to show outcomes or relative importance of library collections and readings to the purpose of reading. In a study of over 1400 academic faculty in seven universities in the United States and Australia (Tenopir et al, 2009b), over half of the scholarly article readings were reported to be for the purpose of research. Faculty members read articles for many other purposes, however, including teaching (20\% of readings), writing proposals (11\%), current awareness/keeping up (9\%), and other purposes (9\%). Article readings for research are more likely to come from the library's collections (50\% from the library) than are readings for current awareness (only 30\% from the library) or teaching (38\% from the library).

Readings for the purpose of writing proposals are more likely to be rated as absolutely essential to that purpose, followed by writings for the purpose of research. Readings for administration or current awareness are rated as less valuable. Readings from the library are also more likely to be rated as absolutely essential to the principal purpose. Purpose of reading is a predicator of format of the reading, where the reading was obtained, and the value of reading (Tenopir et al, 2009b). By asking faculty to reflect on their specific article readings, we can conclude that readings for the purpose of research are more likely to be:

- Rated "absolutely essential"

- Found by searching

- From electronic sources

- From the library e-journal collection.

Outcomes from reading are another explicit value of the collection. From nearly 900 respondents in the United States (Tenopir et al, 2009a), readings were found to:

- Inspire new thinking (55\% of readings)

- Improve results (40\% of readings)

- Narrow, broaden, or change the focus (27\% of readings) 
- Resolve technical problems (12\% of readings)

- Save time (12\% of readings)

- Lead to faster completion of the task at hand (7\% of readings)

- Foster collaborations (6\% of readings)

- Waste the time of the reader $(<1 \%$ of readings)

Qualitative methods can add to information on the value and outcomes of library collections and services (McClanahan et al, 2010). In studies of academic faculty in universities in North America, Australia, China, Korea, Japan, and Western Europe thousands of faculty members contributed comments about how access to e-journal articles has helped improve the efficiency of their work and the quality of their writing, research, and teaching. For example:

- "E-access is essential for scientific writing."

- "I could not do the kind of research or teaching I do without these resources."

- "Access has made collecting research resources infinitely more efficient: and facilitated interdisciplinary research."

- "[e-access] saves me a lot of time which can be used for more extensive reading."

- "I guess that on average the online access saves me more than 10 hours per week."

- "The convenience of desktop delivery has improved my efficiency and dare I say it my ability to be a better researcher and teacher."

Such comments enrich quantitative results and provide additional evidence of the value that the library and access to e-collections brings. Faculty members rely on access to e-articles to improve their research, teaching, and other work. Convenient access to high quality scholarly articles improves research in the present and also into the future not only by saving them time in finding relevant information, but also by fostering collaborations and improving research ideas.

\section{Return on Investment}

Return on investment (ROI) is a method to quantify and demonstrate the amount of income ("return") to the institution that the library contributes, compared to the budget or monetary investment the institution makes in the library. Luther (2008) defines ROI "as a return value 
for the life of the investment, not just a gain or loss, or the year-to-date return" (p.5). It is derived from multiple sources of data, including library budget data, income data from grants or other sources, surveys of faculty perceptions, and interviews with administrators.

ROI is useful not only to measure current values of the library to the institution. ROI measures can also help librarians guide change and set priorities into the future. New scholarly endeavors, such as the library's role in e-science, collaborative scholarship, and institutional repositories cut across all of the traditional functional areas. If a library cannot provide all old and new services, it is helpful to use techniques such as ROI to help set priorities of services.

In a series of studies over time, an international team of researchers, librarians, and publishers are working on demonstrating that for every monetary unit spent on the library, the university receives income back in the form of additional grants income or donations. It can also be used to demonstrate long term value to the community from an educated work force, more productive faculty, or more successful students and graduates. ROI must be articulated within the mission and objectives of the specific institution. Any ROI project must be measurable, replicable both in the same institution and in others, and meaningful (and interesting) to funders (Kaufmann, 2008).

A case study at the University of Illinois tested just one aspect of ROI; that is the value of the library in the grants process - proposals, the return in grant funding, and grants reporting. The project focused on grants income because it has a definable source of income, is a priority in research libraries, and has identifiable data that can be collected. By taking the yearly library budget, adding grants income that allowed calculating the average income from a funded grant and comparing that to faculty members' responses to the importance of citations in the grant proposal and the percentage of the citations that came from articles they accessed through the library's e-journals system, an ROI from the library's contribution to the grants process was calculated. This study found that for every dollar invested in the library, the library contributed to a return of $\$ 4.38$ in successful grant proposals (Luther, 2007). This is just the value in grants--total ROI will be greater.

A follow-up study kept the same focus on grants and grant funding expanding internationally to eight more institutions in eight countries to test how replicable the methods and finds of phase 1 are in a wider context (Tenopir et al, 2010). In both phases 1 and 2 quantitative and qualitative data were gathered directly from faculty through a survey; while data on the number and value of grant proposals, funded grants, and library budget figures were obtained from the university research and budget offices. Interviews with administrators both guided what 
is important and provided additional qualitative input on the value of the library.

The University of Illinois is a major research university with a long tradition of grants. The second study tested to see if the method works in other universities and is applicable in other countries. ROI varied at the eight institutions from 15.5:1 at a scientific research institute in Western Europe to under 1:1 at a comprehensive teaching and research university in Asia that has many humanities courses. In most institutions, the ROI from the library e-journals in grants income was 1.3:1 to 3.4:1 (Tenopir et al, 2010).

\section{Administrators' Priorities}

Interviews with administrators at the University of Illinois (phase 1) and the eight other institutions (phase 2) helped gather information on what they value and how the library can help contribute to the mission of the university in terms that are meaningful to administrators. Several themes emerged in almost all of the nine institutions. Administrators and libraries can work together to:

- Attract outstanding faculty,

- Retain outstanding faculty,

- Foster innovative research,

- Build research reputation of institution, and

- Promote seamless integration of the library with institutional research activities.

Evidence gathered in the phase 1 and 2 studies and in other recent research studies provides a compelling story of how libraries and scholarly collections help with these goals. Some examples of how to present evidence on the value of the library in terms that are meaningful to administrators are provided here:

- Faculty with more publications and more citations obtain more grants (Ali \& Bhattacharyya).

- Faculty who publish more read more (Tenopir \& King, 2000).

- Faculty who receive awards read more (Tenopir \& King, 2000).

- A doubling in article downloads, from 1 to 2 million, is statistically associated with dramatic increases in research productivity (Research Information Network, 2009).

- Open ended comments in Phase 2 from faculty members speak to how important a high quality library is to their work, such as these comments: 
- "I would leave this university in a microsecond if the library deteriorated." - U.S. University

- "I am now able to explore and trace back topics and check the developments that arose along the topic history making connections that were only dreams a few years ago." -Western European Research Institute

- "With the current workload, I could not continue with research without the convenience of access from my own computer." - South African University

- In the phase 2 study surveys, faculty reported that for every article cited, 27-40 more are read on average (Tenopir et al, 2010).

- In 1 university, over 10 years a 1\% increase in library budget correlates with a 1.07\% increase in grant funding (Tenopir et al, 2010).

- In another, over 10 years a $1 \%$ increase in library budget correlates with a 1.21\% increase in grant funding (Tenopir et al, 2010).

\section{Lib-Value}

Phases 1 and 2 both have the narrow focus of looking just at grants and grants income. The main difference is the scope - from a single research institution to eight institutions. A follow-on project, called Lib-Value and funded by the U.S. Institute of Museum and Library Services (IMLS), is broadening the focus dramatically by looking at multiple values of the university libraries, multiple ways that the library provides returns on investment and value, and multiple measures (http://libvalue.cci.utk.edu/). Lib-Value is looking at the contribution of the library to the university's functional areas of research, teaching/learning, and socialization or community building. It is examining many different library collections, services, and physical space issues. Lib-Value team members include:

- Information science researchers, statisticians, and economists (University of Tennessee, Bryant University, and Syracuse University)

- University librarians (University of Illinois Urbana-Champaign, University of Tennessee, University of Pittsburgh, Syracuse University, and selected other universities in New York) and

- Research library statisticians and researchers (Association of Research Libraries). 
The Lib-Value team is testing various functions and multiple methods to measure academic library value, outcomes, and ROI in at least eight academic libraries for multiple stakeholders (including faculty, students, administrators, alumni, and donors). The functional areas to be studied are depicted in 〈figure 1〉.

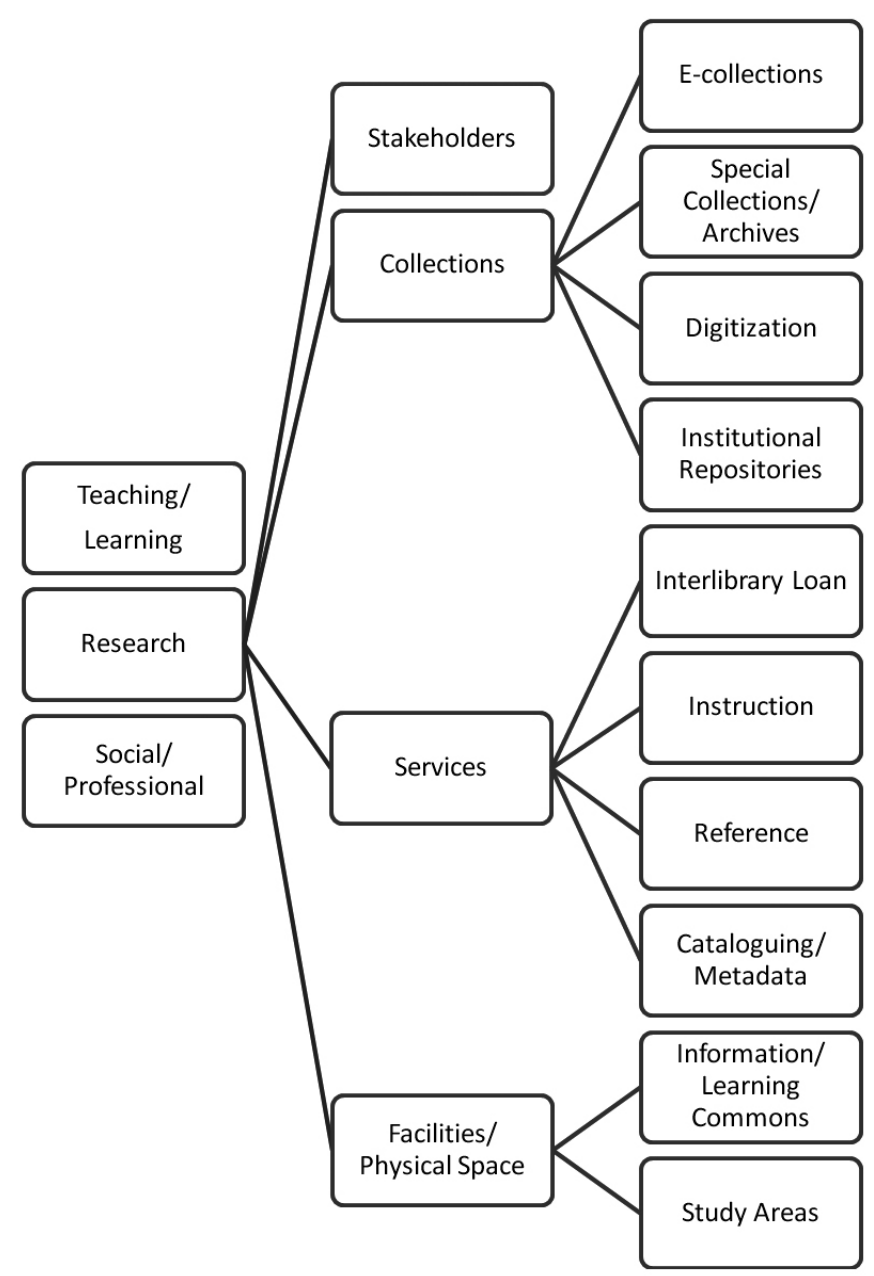

〈Figure 1〉 Map of Functional Areas Included in the Lib-Value Project

Studies for Lib-Value are now underway, including:

- Tina Chrzastowski, Wendy Shelburne, and Paula Kaufman (UIUC) will study value and $\mathrm{ROI}$ as it relates to e-books. This project will incorporate a portion of the "Elsevier E-books Usage and Value Study" currently underway at several universities and corporations, 
including UIUC. Data collection is currently ongoing. Data analysis of focus group feedback, e-book logbooks and usage logs, as well as use data by subject and publisher, will begin fall 2010. The projected completion date for this portion is late 2011.

- Gayle Baker, Teresa Walker, and Ken Wise (UT) will study the value of Information Commons areas. They are currently developing survey instruments as well as negotiating partnerships with other departments at UT to share data and workload. Surveys will be deployed and interviews conducted in September and October of 2010 and data analysis will begin in November.

- Rachel Fleming-May and Crystal Sherline (UT) will look at value and ROI in the functional area of teaching/learning. Interviews, focus groups, and survey instrument development will take place August-December 2010 with an experimental-design study of impact/outcomes of library instruction on learning commencing January 2011 and continuing through May 2011.

- Carol Tenopir (UT) and Donald King (Bryant University and UT) will update a 2002 cost study and readership study at the University of Pittsburgh. In addition to collecting longitudinal data that will inform the understanding of how costs are affected by rapidly changing procedures at academic libraries, this study will examine the link between use of the library's collections to success, productivity, recruitment, and retention of faculty and students. Survey instruments are currently being refined and will be deployed in October of 2010 with preliminary findings available in early 2011.

- Ken Wise and Gayle Baker (UT) will examine the value of Special Collections to the university in terms of their role in donations from alumni and the community, recruitment of faculty and students, and public relations and prestige of the university in the academic community and goodwill in the wider community. Interviews and online pop-up surveys will be deployed and use data collected in September-October 2010, with analysis beginning in November.

- Bruce Kingma (Syracuse University) has coordinated wider participation among New York state libraries, in collaboration with Nylink. He is also working with all members of the team to assess potential economic measures in all studies, as well as developing survey instruments to deploy in the New York state study. This study will cover the economic value of the library in a comprehensive way, including social value and environmental value, examining the potential positive environmental impact of things such as providing online access to resources, paperless resources, etc. This study is also currently in development 
with data collection to begin in Fall 2010.

- Martha Kyrillidou and the team at ARL are engaged in multiple aspects of the project, such as raising public awareness of Lib-Value and the importance of library assessment measures; developing web-based tools for implementing the team's developed models and metrics; and integrating previously collected data into ARL tools already in existence.

An extensive literature review will supplement the studies and measures conducted directly by the Lib-Value team members.

A major challenge for Lib-Value is to develop downstream measures for the outcomes of access to the library collections and services. Within each functional area of research, teaching, and service, the further downstream the more difficult the measure is. For example, how can a value be assigned to the library role in student success or for placement? Libraries can and do measure inputs and outputs; outcomes and ROI are the real challenge. Phases 1 and 2 show that academic library collections help faculty be productive and successful; libraries help generate grants income; and e-collections are valued by faculty and bring value to the university.

\section{Conclusion}

$\mathrm{ROI}$ is only one method for measuring the value of a library's collections and services. The benefit of multiple methods is that numbers in and of themselves rarely tell the full story. Interviews and surveys allow the faculty to tell their story of how they use the library in their grant proposal process, in teaching, and in their research and work life. What we hope to show as the studies progress is that the library's products and services help faculty be successful, help students be successful, and generate both immediate and downstream income that provides good return for the investment.

For a complete picture of users, use, and future needs, libraries must use multiple methods gathered on a regular schedule. Usage logs to get information on use of e-collections, surveys to get opinions, preferences, and behaviors of individuals, and critical incident questions or experiments, and focus groups to get ideas for the future and preferences. The described here are testing multiple methods in academic libraries worldwide to help librarians select measures and methods that are appropriate for the institution and the mission of their organization. 


\section{References}

[1] Ali, M. M., \& Bhattacharyya, P. [n.d.]. Research grant and faculty productivity nexus: heterogeneity among dissimilar institutions. Academic Analytics. in press.

[2] Jones, D. Y. 2007. "How much do the "best' colleges spend on libraries?" College \& Research Libraries, 68(4): 343-351.

[3] Kaufmann, P. 2008. "The Library as Strategic Investment: The University of Illinois 'Return on Investment Study' from the Director's Perspective." Presented at the LibraryConnect 2008 Seminar, Tokyo: Japan. [online]. [cited 2009. 7. 11].

〈http://www.ideals.uiuc.edu/bitstream/handle/2142/8770/LC08_ROILibraryDirectors Tokyo.pdf?sequence. $>$.

[4] King, D.W., Aerni, S., Brody, F., Herbison, M., \& Knapp, A. 2004a. "Comparative costs of the University of Pittsburgh electronic and print library collections." The Sara Fine Institute for Interpersonal Behaviour and Technology. [online]. [cited].

$\langle$ http://web.utk.edu/ tenopir/research/survey_instruments.html〉.

[5] King, D.W., Aerni, S., Brody, F., Herbison, M., \& Knapp, A. 2004b. "The use and outcomes of university library print and electronic collections." The Sara Fine Institute for Interpersonal Behaviour and Technology. [online]. [cited].

$\langle$ http://web.utk.edu/ tenopir/research/survey_instruments.html〉.

[6] King, D.W., Tenopir, C. \& Clarke, M. 2006. "Measuring total reading of journal articles." D-Lib, 12(10). [online]. [cited]. 〈http://www.dlib.org/october06/King/10King.html〉.

[7] Luther, J. 2007. "University Investment in the Library: What's the Return? A Case Study at the University of Illinois at Urbana-Champaign." [online]. [cited 2009. 7. 11]. 〈http://libraryconnect.elsevier.com/whitepapers/0108/lcwp010801.html〉.

[8] Luther, J. 2008. "University investment in the library: What's the return? A case study at the University of Illinois at Urbana-Champaign." Library Connect White Paper no. 1. Elsevier, San Diego: CA. [online]. [cited].

〈http://libraryconnect.elsevier.com/whitepapers/0108/lcwp010801.html〉.

[9] Matthews, J. R. 2007. Library assessment in higher education. Westport, CT: Libraries Unlimited.

[10] McClanahan, K., Wu, L., Tenopir, C., \& King, D.W. 2010. "Embracing change: perceptions of e-journals by university faculty members." Learned Publishing, 23(3): 44-57. 
[11] Mezick, E. M. 2007. "Return on investment: libraries and student retention." Journal of Academic Librarianship, 33(5): 561-566.

[12] Nicholas, D., Huntington, P., Jamali, H., \& Tenopir, C. 2006. "Finding information in (very large) digital libraries: a deep log approach to determining differences in use according to method of access." Journal of Academic Librarianship, 32(2): 119-126.

[13] Research Information Network. 2009. "Ejournals: their use, value, and impact." A Research Information Network Report in collaboration with Ciber, London, RIN, April 2009. [online]. [cited]. 〈http://www.ucl.ac.uk/infostudies/research/ciber/RINejournals.pdf〉.

[14] Strouse, R. 2003. "Demonstrating value and return on investment: The ongoing imperative - Assessing your library's value statement." Information Outlook, 7(5): 14-19.

[15] Tenopir, C. 2009a. "Measuring the value of the academic library: Return on Investment and other value measures." The Serials Librarian, 58(1-4): 39-48.

[16] Tenopir, C. 2009b. “The Value Gap.” Library Journal, 134. [online]. [cited]. 〈http://www.libraryjournal.com/lj/technology/onlinedb/855262-299/the_value_gap.html.csp〉.

[17] Tenopir, C. 2009c. "Measuring the value and return on investment of academic libraries." Paper presented at the International Conference on Academic Libraries (ICAL), Delhi: India.

[18] Tenopir, C., \& King, D.W. 2000. Towards electronic journals: Realities for scientists, librarians, and publishers. Washington, DC: Special Libraries Association.

[19] Tenopir, C., \& King, D.W. 2007. "Perceptions of value and value beyond perceptions." Serials, 20(3): 199-207.

[20] Tenopir, C., King, D.W., Wu, L., \& Edwards, S. 2009a. "Electronic journals and changes in scholarly article seeking and reading patterns." Aslib Proceedings: New Information Perspectives, 61(1): 5-32.

[21] Tenopir, C., King, D. W., Spencer, J., \& Wu, L. 2009b. "Variations in article seeking and reading patterns of academics: what makes a difference?" Library and Information Science Research, 31(3): 139-148.

[22] Tenopir, C., Love, A., Park, J., Wu, L., Baer, A., \& Mays, R. 2010. "University investment in the library, phase II: An international study of the library's value to the grants process." Elsevier. [online]. [cited 2010. 7]. 〈http://libraryconnect.elsevier.com/whitepapers/roi2/lcwp021001.html〉.

[23] Tenopir, C., Read, E., Manoff, M., Baker, G., Nicholas, D., \& King, D.W. 2007. "What does usage data tell us about our users?" Online Information 2007 Conference Proceedings, London: Incisive Media, 80-86. 